\title{
ERRATUM in Wilderness Environ Med. 28/2
}

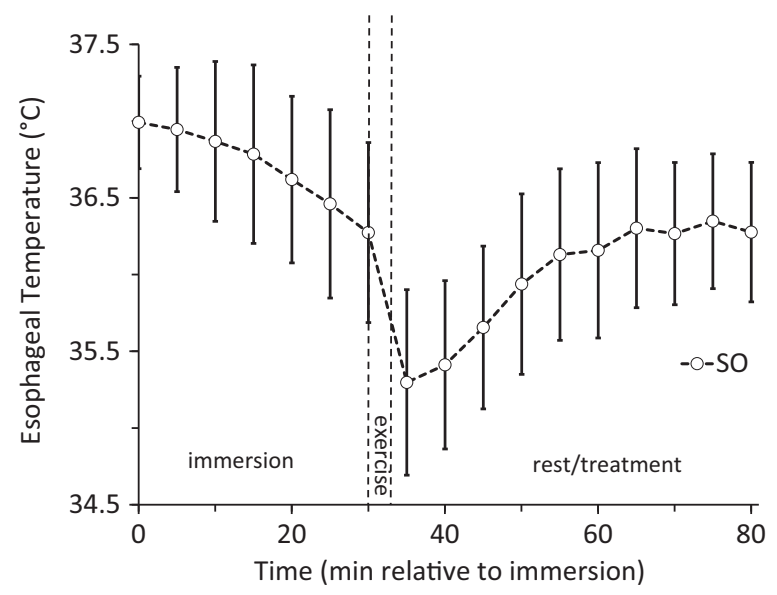

Figure 1. Esophageal temperature (Tes) (mean +/- SD) during 30 minutes of cold water immersion, 5 minutes of postimmersion exercise, and 45 minutes of resting recovery with warming by shivering only $(\mathrm{SO})$.

In the print version of the following article, a portion of Figure 1 and the caption were unreadable due to a print error. We have provided a reprint of the figure and caption above. Christensen ML, Lipman GS, Grahn DA, Shea KM, Einhorn J, Heller HC. A novel cooling method and comparison of active rewarming of mildly hypothermic subjects. Wilderness Environ Med. 2017;28:108-115. http://dx.doi.org/10.1016/j.wem.2017.02.009. 